\title{
Reducing catheter-associated urinary tract infections: a systematic review of barriers and facilitators and strategic behavioural analysis of interventions
}

Lou Atkins ${ }^{1 *}$, Anna Sallis², Tim Chadborn², Karen Shaw², Annegret Schneider ${ }^{1}$, Susan Hopkins², Amanda Bunten², Susan Michie ${ }^{1}$ and Fabiana Lorencatto ${ }^{1}$

\begin{abstract}
Background: Reducing the need for antibiotics is crucial in addressing the global threat of antimicrobial resistance. Catheter-associated urinary tract infection (CAUTI) is one of the most frequent device-related infections that may be amenable to prevention. Interventions implemented nationally in England target behaviours related to catheter insertion, maintenance and removal, but the extent to which they target barriers to and facilitators of these behaviours is unclear.

This strategic behavioural analysis applied behavioural science frameworks to (i) identify barriers to and facilitators of behaviours that lead to CAUTI (CAUTI-related behaviours) in primary, community and secondary care and nursing homes; (ii) describe the content of nationally adopted interventions; and (iii) assess the extent to which intervention content is theoretically congruent with barriers and facilitators.
\end{abstract}

Methods: A mixed-methods, three-phased study: (1) systematic review of 25 studies to identify (i) behaviours relevant to CAUTI and (ii) barriers to and facilitators of CAUTI-related behaviours, classified using the COM-B model and Theoretical Domains Framework (TDF); (2) content analysis of nationally adopted CAUTI interventions in England identified through stakeholder consultation, classified using the Behaviour Change Wheel (BCW) and Behaviour Change Techniques Taxonomy (BCTTV1); and (3) findings from 1 and 2 were linked using matrices linking COM-B and TDF to BCW/BCTTV1 in order to signpost to intervention design and refinement.

Results: The most frequently reported barriers to and facilitators of CAUTI-related behaviours related to 'environmental context and resources'; 'knowledge'; 'beliefs about consequences'; 'social influences'; 'memory, attention and decision processes'; and 'social professional role and identity.'

Eleven interventions aiming to reduce CAUTI were identifed. Interventions were primarily guidelines and included on average 2.3 intervention functions (1-5) and six BCTs (2-11), most frequently 'education', 'training' and 'enablement.' The most frequently used BCT was 'information about health consequences' which was used in almost all interventions. Social professional role and identity and environmental context and resources were (Continued on next page)

\footnotetext{
* Correspondence: l.atkins@ucl.ac.uk

${ }^{1}$ Centre for Behaviour Change, University College London, Alexandra House,

7-19 Queens Square, London WC1N 3AZ, UK

Full list of author information is available at the end of the article
}

C C The Author(s). 2020 Open Access This article is licensed under a Creative Commons Attribution 4.0 International License, which permits use, sharing, adaptation, distribution and reproduction in any medium or format, as long as you give appropriate credit to the original author(s) and the source, provide a link to the Creative Commons licence, and indicate if changes were made. The images or other third party material in this article are included in the article's Creative Commons licence, unless indicated otherwise in a credit line to the material. If material is not included in the article's Creative Commons licence and your intended use is not permitted by statutory regulation or exceeds the permitted use, you will need to obtain permission directly from the copyright holder. To view a copy of this licence, visit http://creativecommons.org/licenses/by/4.0/. The Creative Commons Public Domain Dedication waiver (http://creativecommons.org/publicdomain/zero/1.0/) applies to the data made available in this article, unless otherwise stated in a credit line to the data. 
(Continued from previous page)

targeted least frequently with potentially relevant BCTs.

Conclusions: Interventions incorporated half the potentially relevant content to target identifed barriers to and facilitators of CAUTI-related behaviours. There were missed opportunities for intervention as most focus on shaping knowledge rather than addressing motivational, social and environmental influences. This study suggests that targeting motivational, social and environmental influences may lead to more effective intervention design and refinement.

Keywords: Catheter-associated urinary tract infection, CAUTI, Theory, Behaviour change wheel, Strategic behavioural analysis, Behaviour change techniques, Theoretical domains framework

\section{Contributions to the literature}

- Catheter-associated urinary tract infection is one of the most prevalent healthcare-associated infections, but it is unclear on the extent to which influences on CAUTI-related behaviours are targeted in current interventions.

- We found half the potentially relevant content to target identified barriers and facilitators in interventions but strategies to target motivational, social and environmental influences were largely missing in favour of those targeting knowledge.

- To our knowledge, this is the first attempt to apply theorybased, behavioural tools in the context of policy to identify influences on behaviour and assess the match between influences on behaviour and intervention content.

\section{Background}

Improving infection prevention and control (IPC) is a crucial step in addressing the global health threat of antimicrobial resistance $[1,2]$. Reducing the need for antibiotic use by preventing infections occurring requires behaviours to change in health care professionals (HCPs), patients and the general population across healthcare settings, e.g. primary, secondary and community care and nursing homes. Relevant HCP behaviours include keeping hands, equipment and environments clean, observing IPC protocols during invasive medical procedures (e.g. surgery, inserting catheters and other devices), continence care, and avoiding breach in skin or mucous membranes. Urinary tract infection (UTI) is one of the most common healthcare associated infections with approximately half associated with the presence of a urinary catheter [3]. These infections can be acquired by unnecessary use, poor insertion technique that can introduce bacteria, and leaving a catheter in too long allowing bacteria to travel up the catheter to the bladder causing UTI and potentially onward into the blood.

Catheter-associated urinary tract infections (CAUTI) are a product of a complex set of interrelated behaviours performed by multiple individuals. In the English $\mathrm{Na}$ tional Health Service (NHS), interventions targeting behaviours that prevent CAUTI have been implemented at different levels from national evidence-based guidelines to local interventions to implement these guidelines. Some of these have been widely adopted across the country such as the Houdini protocol [4] (seven criteria for nurse-driven decision-making on catheter removal) and the catheter passport (patient-held record of catheter decision-making and care) [5].

It is not currently known on the extent to which barriers to and facilitators of behaviours related to CAUTI are targeted in current interventions. This is a notable gap considering interventions which target factors influencing behaviour (barriers and facilitators) are more likely to be effective in achieving behaviour change [6]. Investigating this can be facilitated by applying behavioural theory and evidence-based tools to determine the congruence (i.e. the match) between intervention content and barriers to and facilitators of CAUTI-related behaviours. Exploring theoretical congruence in the context of already widely implemented interventions enables strategic identification of opportunities for intervention and policy refinement. We termed this process 'strategic behavioural analysis.'

Tools such as the behaviour change wheel, which includes the theoretical model of behaviour COM-B (Fig. 1), the Theoretical Domains Framework (TDF), and the Behaviour Change Techniques Taxonomy (BCTTv1), may be specifically useful for describing intervention content and for investigating congruence between barriers to and facilitators of behaviour. Figure 2 shows how the TDF domains are linked to COM-B with the 14 more detailed domains and their associated constructs sitting within the broader COM-B model [see Additional file 1 for labels, definitions and examples for COM-B and TDF].

The behaviour change wheel (BCW), a synthesis of 19 frameworks of behaviour change, can be used to characterise interventions. COM-B sits at the 'hub' of the wheel and is surrounded by nine intervention functions, i.e. purposes an intervention serves and seven policy categories, i.e. channels through which interventions might 


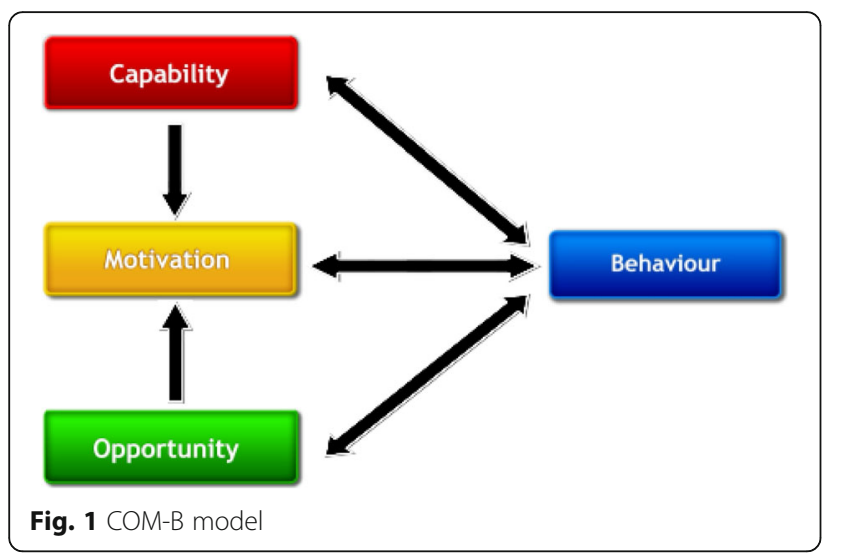

be delivered (Fig. 2; see Additional file 2 for labels and definitions) [7]. Different intervention functions and policy categories are likely to be differentially effective depending on the extent to which capability, opportunity and/or motivation need to change [see Additional file 3 for matrices linking COM-B to intervention functions and policy categories].

How intervention functions are delivered can be described using a 93-item taxonomy of behaviour change techniques (Behaviour Change Techniques Taxonomy v1-BCTTv1) [8]. Links between intervention functions and BCTs (i.e. which BCTs might be considered to serve each intervention function) are described by Michie et al. 2014 [9].

Typically, these have been used to design new interventions. However, where there are already interventions in place that may not be working optimally, these tools have been applied to refine established interventions [10] and in guiding evidence synthesis of published evidence on interventions and barriers to and facilitators of behaviour. For example, the WIDeR-EyeS project (What Works to Increase Attendance for Diabetic Retinopathy Screening? An Evidence sYnthEsiS) conducted two reviews, one of interventions to increase attendance for diabetic retinopathy screening which were coded using BCTTv1 [11] and one of barriers to and facilitators of screening attendance, coded using TDF [12]. Findings from these reviews were compared using linking matrices to assess the extent to which BCTs in interventions targeted relevant barriers to and facilitators of the behaviours they were intended to change [13]. Using this method, the authors identified barriers to screening that were not targeted by the intervention BCTs, for example, emotional barriers.

This study had the following aims:

1. Identify barriers to and facilitators of CAUTIrelated behaviours in HCPs

2. Describe the content of nationally adopted interventions in England to reduce CAUTI

3. Establish the extent to which barriers to and facilitators of CAUTI-related behaviours are targeted by nationally adopted interventions

\section{Methods}

This mixed-methods study was conducted over three phases, each relating to one of the aims. Phase 1 was a

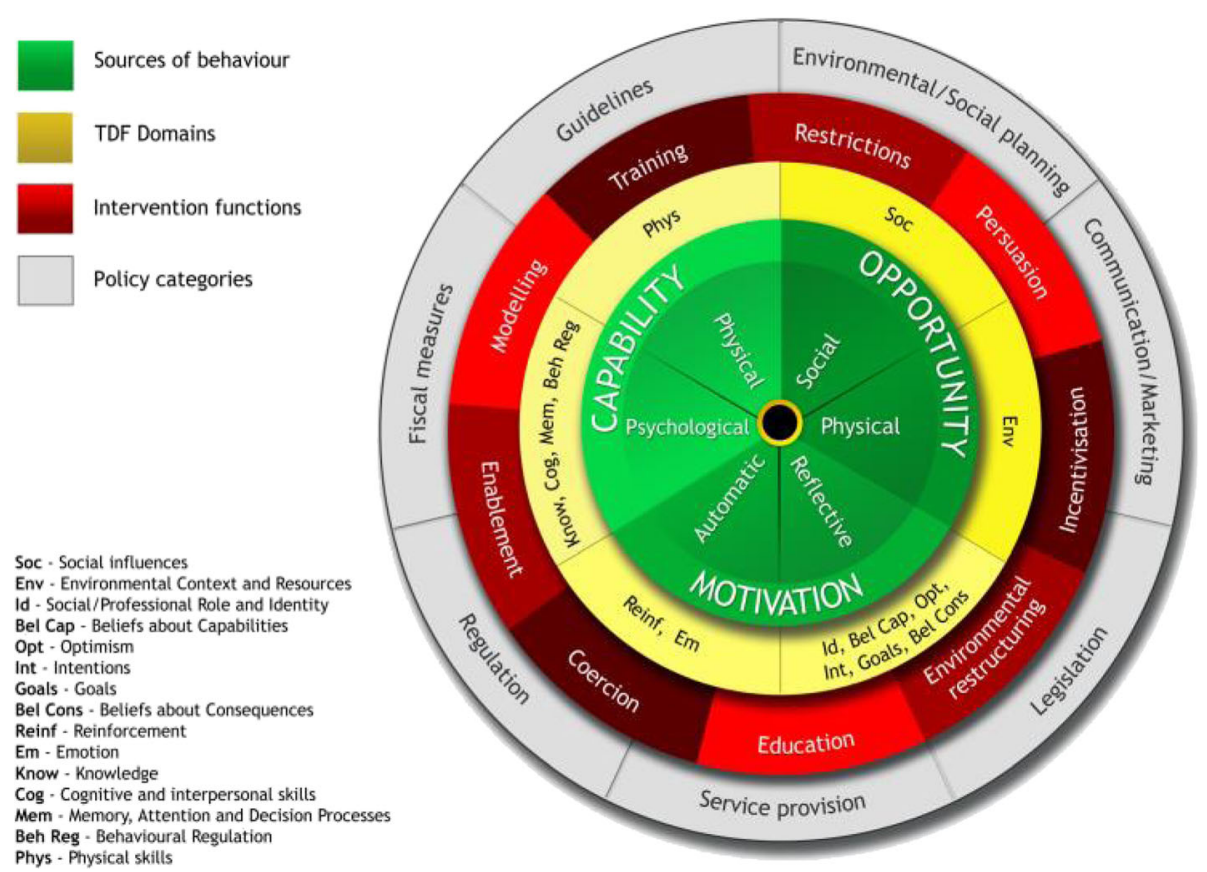

Fig. 2 TDF domains linked to COM-B within the Behaviour Change Wheel 
systematic review of barriers to and facilitators of CAUTI-related behaviours, phase 2 was a content analysis of nationally adopted interventions in England to reduce CAUTI and phase 3 compared findings from phases 1 and 2 to establish the extent to which intervention content was theoretically congruent with the identified barriers to and facilitators of CAUTI-related behaviours.

\section{Aim 1-systematic review of barriers to and facilitators of CAUTI-related behaviours \\ Search strategy and selection criteria}

We conducted a systematic review in accordance with PRISMA guidelines (Additional file 4). We searched MEDLINE, EMBASE and PsycINFO electronic databases in November 2017, limiting searches to 1995 onwards to optimise generalisability to current NHS settings and acknowledge the improvement in the quality of reporting in peer-review literature over time [see Additional file 5 for search strategies]. We included empirical qualitative and/or quantitative research or systematic review articles reporting barriers to and facilitators of CAUTI-related behaviours performed by HCPs in primary, secondary or community care or nursing homes, with titles and abstracts written in English.

\section{Study selection and quality assessment}

Titles and abstracts were screened against the inclusion and exclusion criteria independently by two reviewers. Full texts of studies meeting the inclusion and exclusion criteria were then screened against the same criteria by two reviewers. At both stages, any papers for which the decision was not clear were discussed with other members of the review group. We used the Mixed Methods Appraisal Tool (MMAT) [14] to assess the quality of qualitative, quantitative and mixed-methods studies.

\section{Data extraction tools}

Study characteristics extracted were country, setting, disease, participants, target behaviour and how the target behaviour was measured. Quotes and author interpretations of barriers and facilitators were coded using COM$\mathrm{B}$ and TDF. Data were extracted by LA and checked by FL. Disagreements were resolved by discussion.

\section{Data analysis}

We conducted a three-step framework [15] and thematic [16] analysis to synthesise and explain barriers to and facilitators of CAUTI-related behaviours identified in the systematic review [13]:

1. Framework analysis by deductively coding extracted data according to barriers and facilitators into the
COM-B and TDF domain(s) they were judged to represent best.

2. Thematic analysis within each TDF domain, grouping similar data points and inductively generating summary theme labels.

3. Ranking TDF domains in terms of importance according to frequency (number of studies), elaboration (number of themes) and evidence of conflicting beliefs within domains (e.g. if some participants report lack of knowledge of guidelines whereas others report familiarity with guidelines) [17]. Rank order was determined first by frequency, then elaboration, then evidence of conflicting beliefs.

These data are described using COM-B and TDF, with COM-B offering a higher-level summary and TDF offering a more granular level of analysis.

\section{Aim 2-content analysis of nationally adopted interventions in England to reduce CAUTI Search strategy and selection criteria}

We asked stakeholder delegates at IPC conferences, members of clinical commissioning groups, topic experts from relevant evidence-based guideline development groups and Public Health England Antimicrobial Resistance (AMR) Programme Board) to identify interventions aimed at HCPs to reduce CAUTI; > 100 responded.

\section{Intervention selection and quality assessment}

Interventions were limited to programmes, improvement strategies and policies currently adopted across England where the primary aim was to reduce CAUTI. Interventions that were implemented only locally were not included as the aim of this study was to understand interventions implemented at a national level.

\section{Data extraction tools}

The BCW and BCTTv1 were used to code content identified in materials or descriptions of interventions into intervention functions, policy categories and BCTs. Definitions provided in the BCW and BCTTv1 were referred to throughout the coding exercise to ensure coding was appropriate and consistent.

\section{Data analysis}

For each intervention, we recorded the total number of intervention functions, policy categories and BCTs and calculated the mean and range. We recorded the number of interventions in which each BCT and intervention function was present (mean and range), identified the most and least frequent intervention functions and BCTs and extracted representative examples across interventions. 


\section{Aim 3-investigating congruence by linking identified barriers and facilitators to intervention content}

BCTs are likely to be more or less effective depending on the nature of the barrier or facilitator. 'Theoretical congruence' is a term we use to define the extent to which BCTs in interventions are relevant to barriers and facilitators of behaviours the intervention is intended to change. BCTs can have different levels of congruence. For example, the BCT 'behavioural rehearsal/ practice' is likely to be relevant where there is a lack of capability to perform the behaviour. This would represent high congruence, i.e. a match between intervention content (BCT) and the barrier to the behaviour (lack of capability). In contrast, if lack of motivation was a barrier to the behaviour, then using the $\mathrm{BCT}$ 'behavioural practice/rehearsal' is unlikely to bring about behaviour change; this represents low congruence between intervention content and factors influencing behaviour [18].

Exploring congruence between intervention content and barriers to and facilitators of behaviour can be achieved using matrices which link both the techniques from BCTTv1 and BCW intervention functions to construct domains from both the TDF and COM-B, producing congruent $\mathrm{BCT} \times$ domain pairings. These are based on expert consensus [13].

\section{Data analysis}

This analysis applied a matrix that included the BCT $\times$ TDF pairings published in Cane et al. [19] and Michie et al. [6] to investigate the level of theoretical congruence between the content of interventions targeting CAUTI and the published literature on factors influencing behaviours related to CAUTI [see Additional file 6 for matrix]. To achieve this, we took the following steps:

- Step 1. For each BCT identified in the existing interventions, we then consulted the TDF $\times$ BCT matrix to see which domains it was paired with. We then looked at findings from the systematic review to see whether the domain(s) the BCT was paired with was classified as a key domain. BCTs were then classified as having either:

- Low congruence-did not target any key domains

- Medium congruence-targeted at least one key domain

- High congruence-targeted 2+ key domain s[13]

- Step 2. In addition to investigating the extent to which BCTs identified in interventions were linked to key domains (step 1), we also sought to establish, of the key domains we identified in the systematic review, which potentially relevant BCTs were suggested in the matrix. Some of the BCTs suggested by the matrix may have not been identified in existing interventions; these represent missed opportunities for intervention design. We examined the frequency with which these BCTs were identified in the existing interventions. We classified each potentially relevant BCT as follows:

- Opportunity seized-instances where a theoretically congruent BCT (according to the matrix) was identified in an existing intervention at least once

- Missed opportunity-instances where the theoretically congruent BCT was never identified in existing interventions

- Step 3. As there are multiple ways in which a single behaviour change technique can be delivered, we also examined whether BCTs we identified in interventions were delivered in a way that addressed the specific nature of the barriers and facilitators identified in key TDF domains. For example, if the BCT 'information about health consequences' was delivered in terms of providing information on the severity and complications of CAUTI, but a barrier within the domain 'beliefs about consequences' was the belief that inserting catheters increase convenience for the patient and healthcare professional, this would represent the lack of congruence between the content of the BCT and the identified barriers and facilitators within the corresponding domain; despite, in theory, this BCT being potentially relevant and congruent with this domain.

- We repeated steps 1-3 at the level of BCW intervention functions and policy categories, by consulting the matrices linking BCW to COM-B and TDF [9] to identify the extent to which intervention functions and policy categories in existing interventions target key COM-B and TDF domains influencing behaviour, and what additional intervention functions and policies may be of relevance to addressing barriers and facilitators within the most important domains.

\section{Results}

Systematic review of barriers of and facilitators to CAUTIrelated behaviours

We identified 25 studies which met the inclusion criteria. Table 1 provides a summary of these studies. Seventeen were conducted in the USA with the remainder being conducted in France, Canada, UK, Australia, Taiwan and Thailand. The majority of studies (92\%) were conducted in secondary care (including three in tertiary care). Only one study was conducted in nursing homes and one in community care; therefore, results are presented integrated across care settings [see Additional file 7 for a flow of information through the review]. 


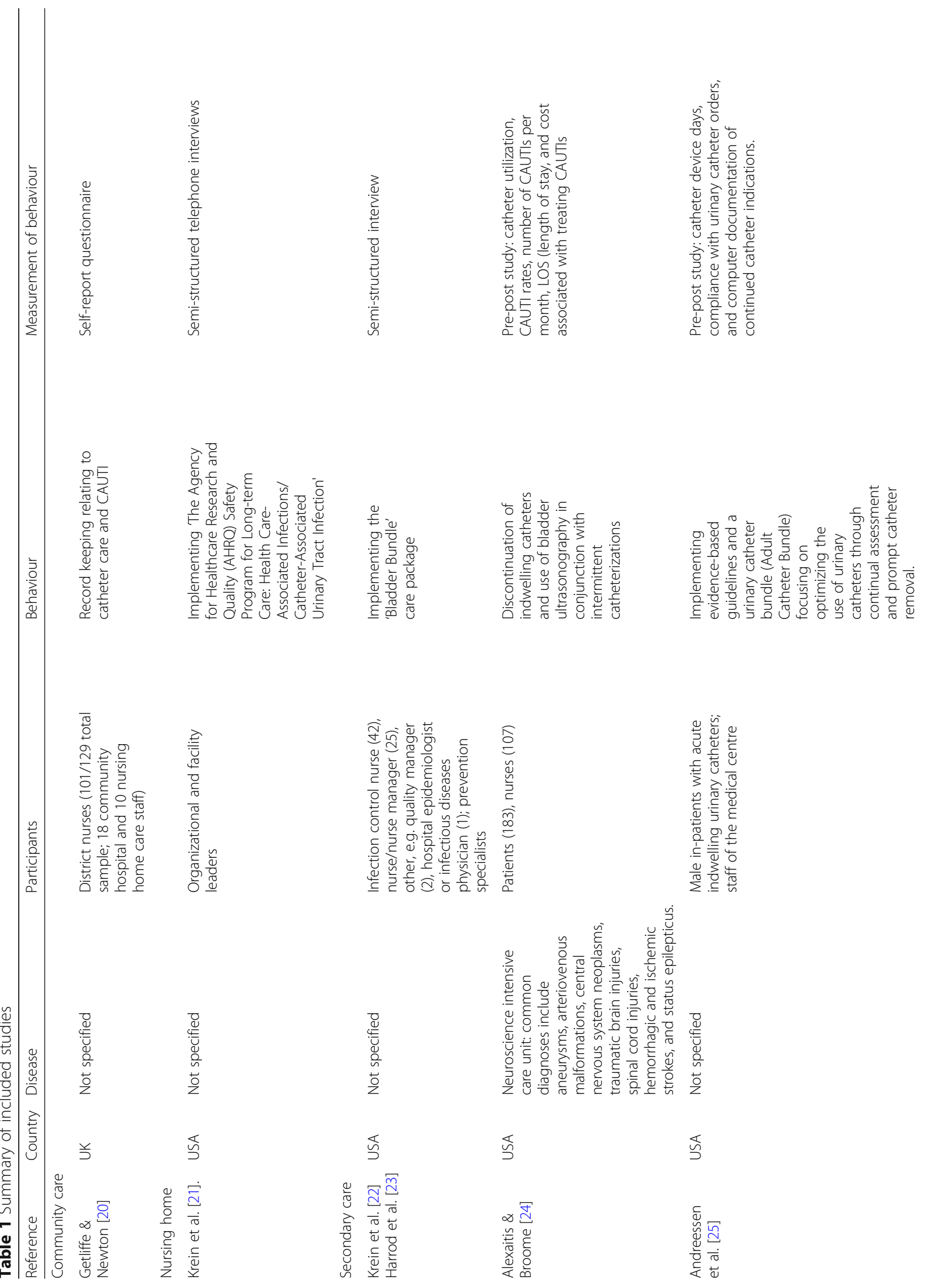




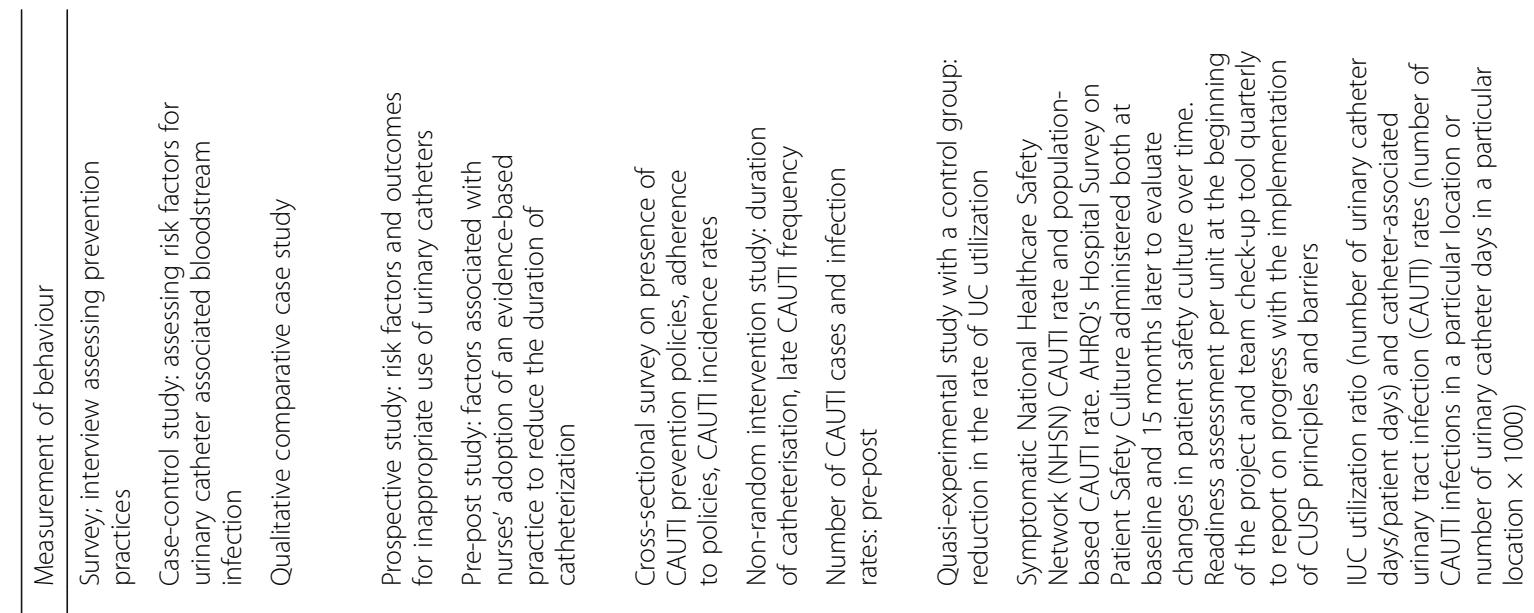

\begin{tabular}{|c|c|c|c|c|c|}
\hline 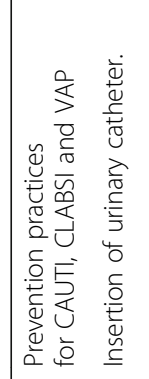 & 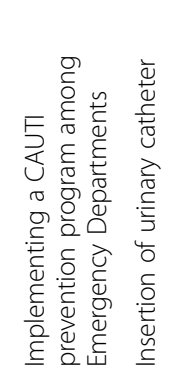 & 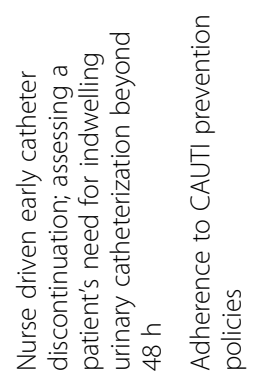 & 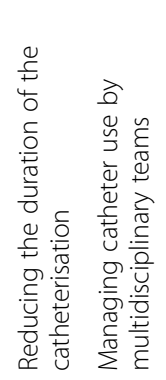 & 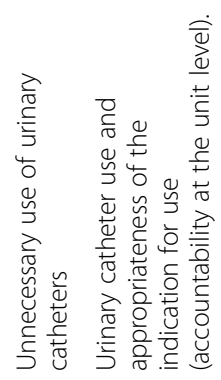 & 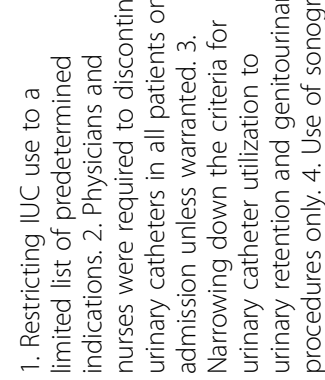 \\
\hline
\end{tabular}

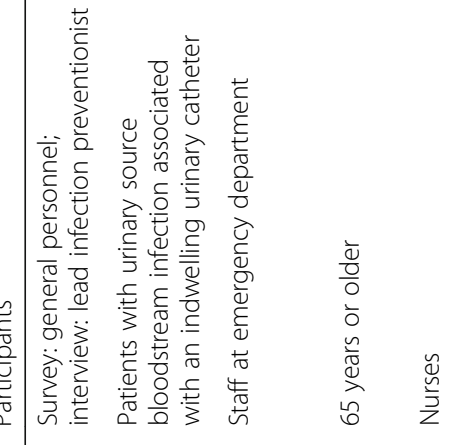
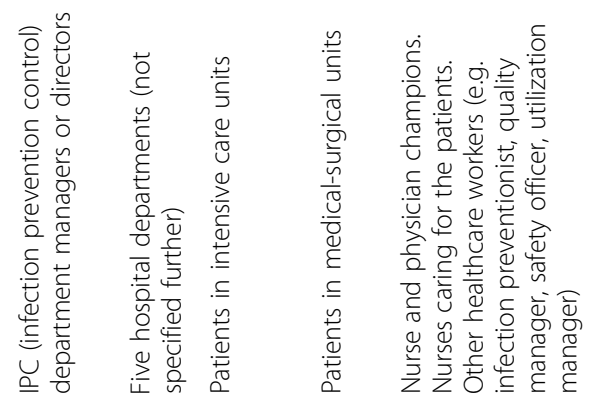

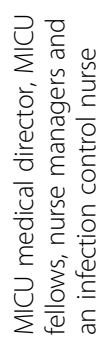




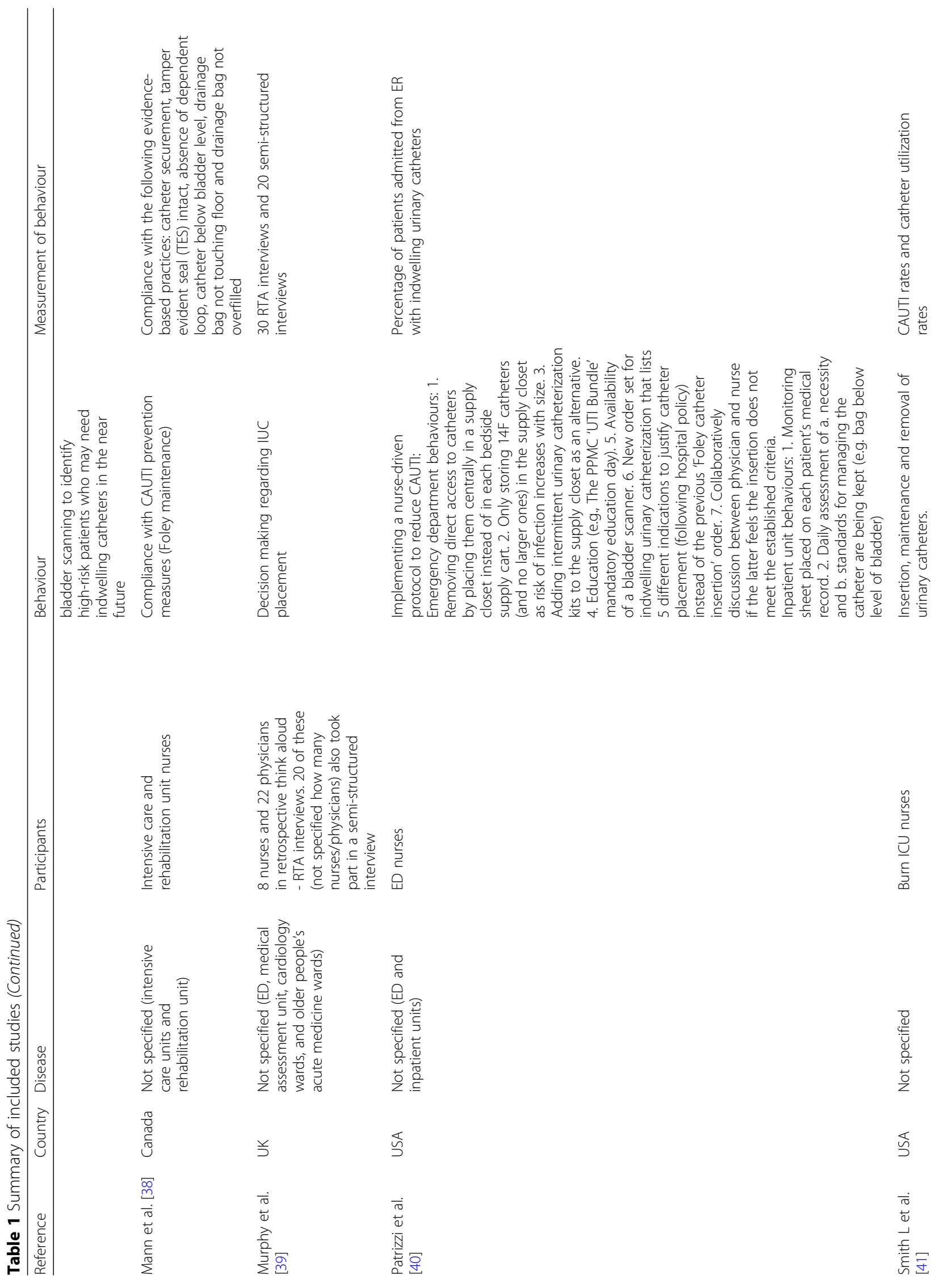




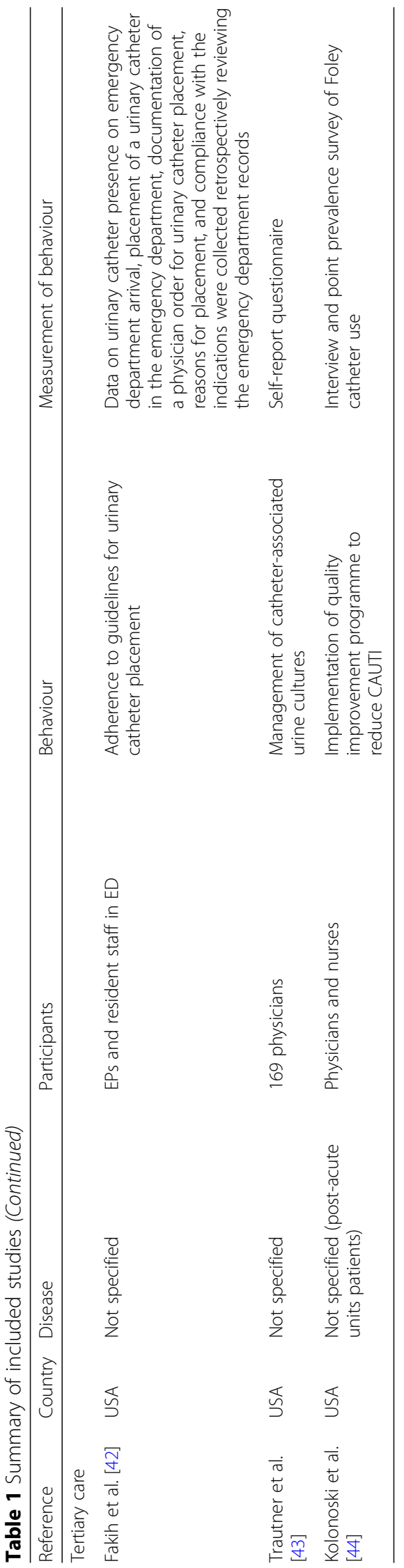


Nine studies used quantitative descriptive designs, nine used qualitative designs, five used mixed methods and two used non-randomised designs. Study quality details are presented in Additional file 8.

Included studies typically focussed on barriers to and facilitators of implementing bundles of behaviours (i.e. multiple related behaviours) as part of interventions rather than individual behaviours (e.g. inserting a catheter, catheter removal, antibiotic prescribing) (Table 1). We summarised these behaviours according to four sequential time periods: pre-insertion of the catheter, insertion, post-insertion maintenance, and removal (see Fig. 3 for behavioural map).

Table 2 provides a ranking of the importance of COM-B and TDF domains identified. Additional file 9 presents the five most frequently identified themes within each COM-B and TDF domain. Table 3 indicates in which settings TDF domains were identified as barriers, facilitators or both. 'Beliefs about capabilities' was identified as a facilitator in secondary and tertiary care. 'Behavioural regulation' was identified as both barrier and facilitator in secondary care. All other identified TDF domains were classified as a mixture of either barrier or both barrier and facilitator across care settings. Additional file 10 contains a full list of all themes per domain, according to each care setting and corresponding CAUTI-related behaviour phase from the behavioural map (i.e. pre- insertion, insertion, post-insertion). The six most frequently identified domains are summarised below.

1. Environmental context and resources $(n=13$ studies): Themes in this domain included 'limited and inconsistent documentation and records relating to urinary catheter use', i.e. absent or inappropriate documentation led to inappropriate catheter use; 'transitions of care,' e.g. when patients were moved between wards; 'lack of time to perform alternatives to urinary catheterisation' such as taking patients to the bathroom; 'lack of available medical alternatives to urinary catheterisation', e.g. a bladder scanner to determine catheter need (all of which were barriers to appropriate catheter usage) and 'choice and availability of urinary catheters' which was variable, i.e. available in some contexts and limited or absent in others, was coded as both a barrier and facilitator.

2. Knowledge ( $n=12$ studies): Barriers to appropriate catheter usage included lack of knowledge of 'clinical guidelines; 'duration of catheter insertion,' i.e. not knowing that a catheter was in place or how long it had been in place; 'risks associated with catheter use'; and 'how to manage patients without catheterisation.' 'Knowledge of how to manage bacterial infections resulting from urinary catheterisation' was classified as a facilitator of appropriate catheter usage.

3. Beliefs about consequences ( $n=12$ studies): Eight themes were identified. The most frequent was

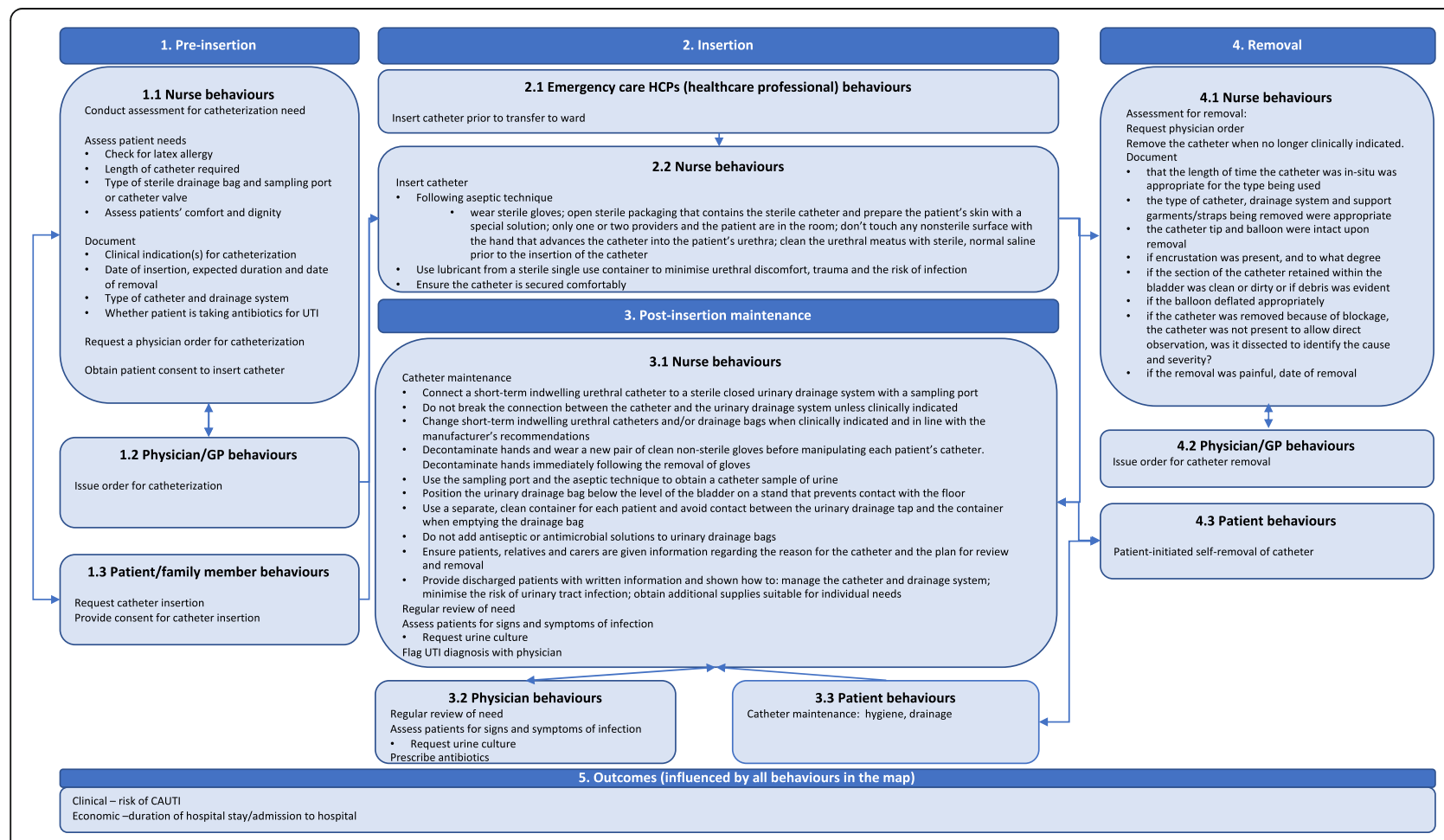

Fig. 3 Map of CAUTI-related behaviours 
Table 2 Ranking of TDF domain importance according to the frequency of identification, thematic elaboration and evidence of conflicting beliefs

\begin{tabular}{|c|c|c|c|c|}
\hline Ranking & TDF domain (COM-B) & $\begin{array}{l}\text { Frequency } \\
\text { (no. of studies identified in; } \\
\max n=25 \text { ) }\end{array}$ & $\begin{array}{l}\text { Elaboration } \\
\text { (number of themes) }\end{array}$ & $\begin{array}{l}\text { Evidence of barriers and/or } \\
\text { facilitators within domains } \\
\text { (Yes/No) }\end{array}$ \\
\hline 1 & $\begin{array}{l}\text { Environmental context and resources (physical } \\
\text { opportunity) }\end{array}$ & 13 & 8 & Yes \\
\hline 2 & Knowledge (psychological capability) & 12 & 9 & Yes \\
\hline 3 & Beliefs about consequences (reflective motivation) & 12 & 8 & Yes \\
\hline 4 & Social Influences (social opportunity) & 9 & 6 & Yes \\
\hline 5 & $\begin{array}{l}\text { Memory, attention and decision processes } \\
\text { (psychological capability) }\end{array}$ & 8 & 8 & Yes \\
\hline 6 & $\begin{array}{l}\text { Social professional role and identity (reflective } \\
\text { motivation) }\end{array}$ & 6 & 4 & Yes \\
\hline 7 & Behavioural regulation & 3 & 2 & Yes \\
\hline 8 & Beliefs about capabilities & 2 & 2 & No \\
\hline \multirow{2}{*}{$\begin{array}{l}\text { Joint 9th and } \\
\text { 10th }\end{array}$} & Skills & 2 & 1 & No \\
\hline & Goals & 2 & 1 & No \\
\hline \multirow{4}{*}{$\begin{array}{l}\text { Joint } 11^{\text {th }}- \\
\text { 14th }\end{array}$} & Reinforcement & 0 & 0 & - \\
\hline & Intentions & 0 & 0 & - \\
\hline & Optimism & 0 & 0 & - \\
\hline & Emotions & 0 & 0 & - \\
\hline
\end{tabular}

'convenience and ease of monitoring,' e.g. inserting catheters for convenience purposes such as for measuring patients' urine output or avoiding transfers to a bedpan or commode, which was identified in five studies. The theme 'perceived severity of CAUTI' was identified in two studies and classified as both a barrier and facilitator as some perceived CAUTI to be common and benign whilst others perceived it to be a potential source of risk for patients. 'Lack of perceived benefits to interventions targeting CAUTI' was identified as a barrier to appropriate catheter usage in two studies.

Table 3 Classification of TDF domains as barriers, facilitators, or both across care settings

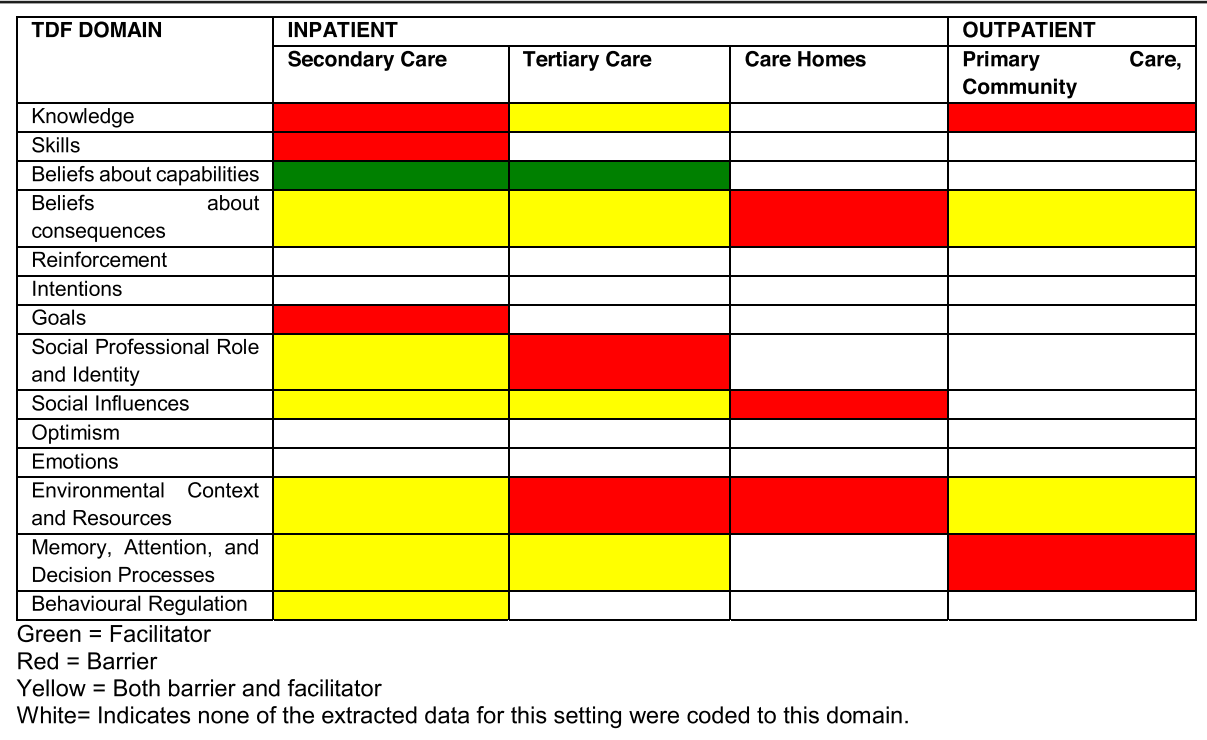


4. Social influences ( $n=9$ studies): Six themes related to this domain were identified. The most frequently identified were 'requests from patients and their carers to have a catheter inserted' (identified as a barrier in five studies); 'lack of peer support and buy-in,' i.e. low engagement amongst HCPs in performing CAUTI-related behaviours; 'physicians dictating nurses' practice,' e.g. nurses complying with physician preference to leave a catheter in position and; and 'cultural norms regarding standard catheterisation practice for specific patient groups,' e.g. a standard practice of inserting a catheter for all patients in intensive care-these three themes were identified as barriers.

5. Memory, attention and decision making ( $n=8$ studies): Eight themes were identified in this domain including 'pre-empting subsequent urinary catheterisation,' i.e. inserting a catheter based on the perception the patient will anyway be catheterised in the future if not now (identified as a barrier in three studies); 'catheterisation decisions based on non-medical criteria,' e.g. to manage incontinence (identified as a barrier in one study); and 'patient symptoms prompting investigation and treatment of possible CAUTI' (identified as a facilitator in one study).

6. Social professional role and identity ( $n=6$ studies): Four themes related to this domain were identified including facilitators such as 'having a hospital epidemiologist in post' and 'nurses leading change in urinary catheterisation practice' and barriers such as 'lack of acceptance of responsibility for urinary catheterisation decision making' or 'not perceiving CAUTI guidelines as relevant across hospital departments.'

\section{Content analysis of nationally adopted interventions in England to reduce CAUTI}

We identified 11 interventions: six were implemented in primary care, seven in secondary care and eight in community care and in nursing homes (see Additional file 11 for intervention name and setting).

Additional file 12 shows the intervention functions, policy categories and BCTS identified in each intervention. Only two interventions targeted all behavioural phases: (i) The Health and Social Care Act 2008 Code of Practice on the prevention and control of infections and related guidance and (ii) Catheter Care: Royal College of Nursing Guidance for nurses. The majority focused on behaviours related to pre-insertion, insertion and postinsertion maintenance rather than removal.

\section{Intervention functions and policy categories identified in interventions}

The mean number of intervention functions per intervention was 2.3 (1-5) (Fig. 4). All identified interventions served the function 'education.' Seven interventions served the function 'enablement' and four served the function 'training.' None of the interventions served the intervention functions 'persuasion,' 'restructuring the environment,' 'restriction' or 'coercion.'

There was a very narrow range of policy strategies identified $($ mode $=1$ ) (Additional file 12 ). The most frequently identified policy category was 'guidelines' $(n=$ 9). One intervention, the 'Health and Social Care Act 2008 Code of Practice on the prevention and control of infections and related guidance' served the policy category 'legislation.' One intervention, the 'Patient Safety Thermometer' served the policy category 'service provision.'

\section{$B C T$ s identified in interventions}

The interventions typically included a narrow range of BCTs. The mean number of BCTs per intervention was 6 (2-11) (see Fig. 5). Many interventions also included 'enablement' functions, through 'goal setting', 'monitoring' and 'feedback' BCTs.

The BCT 'instruction on how to perform the behaviour' was identified in 10/11 interventions. Instruction was typically identified in guidelines, in the form of recommendations to perform the behaviour and how to do so, for a range of behaviours including those related to obtaining patient consent, catheter insertion, maintenance, removal and provision of patient information. The BCT 'information about health consequences' was identified in 9 interventions. Examples of how this BCT was delivered included, explaining that unnecessary treatment with antibiotics can increase the resistance of bacteria that cause urinary tract infections, making antibiotics less effective for future use.

Additional file 13 provides examples of how BCTs were operationalised in interventions

\section{Investigating congruence by linking identified barriers and facilitators to intervention content}

The most frequently identified BCT, 'instruction on how to perform the behaviour,' was observed to have low theoretical congruence as the linking matrix suggests it is congruent with the TDF domain 'skills,' which was ranked a joint 9th out of 14 in terms of importance (Table 2). The second most frequent BCT, 'information about health consequences,' was observed to have high theoretical congruence as it was paired with two TDF domains rated as important-'knowledge' and 'beliefs about consequences.'

Of the 24 BCTs identified in interventions, 10 BCTs had low theoretical congruence, six had medium congruence and nine had high theoretical congruence. BCTs with low congruence included those relating to 'goal setting' and 'review', 'monitoring by others of behaviours or outcomes', 'instruction on how to perform the 


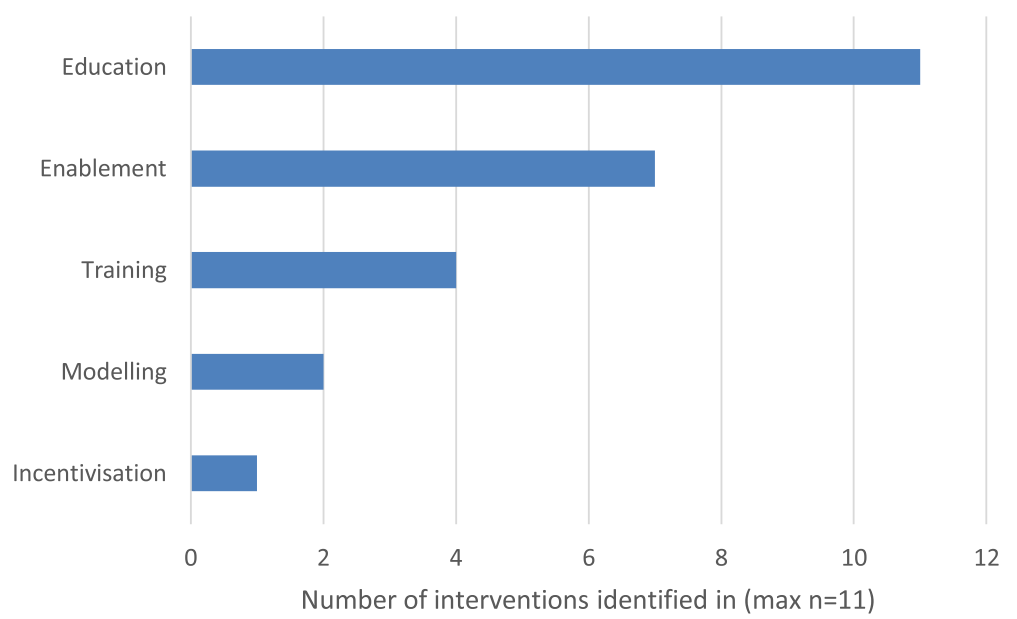

Fig. 4 Frequency of identification of intervention functions

behaviour', 'behavioural practice/rehearsal', 'reward/outcome' and 'reframing' meaning that the BCTs selected to deliver the intervention were not related to any of the TDF domains identified as important in systematic review data linked to barriers and facilitators. BCTs with high congruence related to 'self-monitoring' and 'feedback', 'information about health and social and environmental consequences' and 'restructuring the social environment' meaning that these BCTs would likely address the barriers or enable the facilitators to address the behaviours (see Table 4).

Missed opportunities for intervention design and refinement Table 5 shows whether intervention functions identified in the 11 interventions appropriately targeted the six most important TDF domains. According the matrix TDF

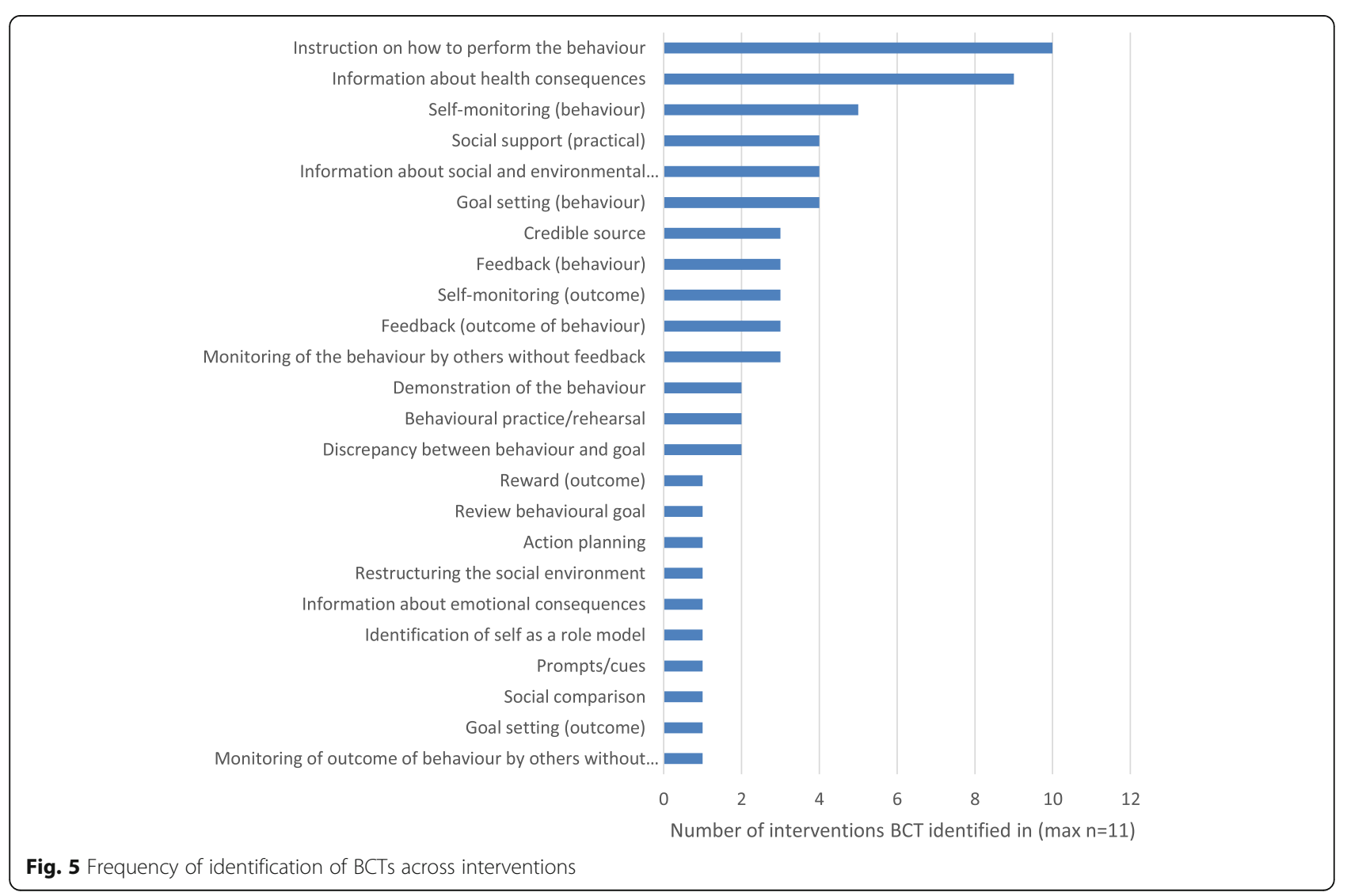


Table 4 Theoretical congruence between BCTs and TDF domains

\begin{tabular}{|c|c|c|c|c|}
\hline BCT & $\begin{array}{l}\text { Frequency } \\
(\boldsymbol{N} \text { interventions, } \\
\text { Max 11) }\end{array}$ & $\begin{array}{l}\text { Linked TDF domains according to } \\
\text { integrated linking matrix }{ }^{\mathbf{a}}\end{array}$ & $\begin{array}{l}\text { TDF domain } \\
\text { importance } \\
\text { ranking }{ }^{\mathbf{b}}\end{array}$ & $\begin{array}{l}\text { Theoretical congruence } \\
\text { between BCT and domain }\end{array}$ \\
\hline \multirow{4}{*}{$\begin{array}{l}\text { Feedback (on outcome of } \\
\text { behaviour) }\end{array}$} & \multirow[t]{4}{*}{3} & Knowledge & 2 & \multirow[t]{4}{*}{ High } \\
\hline & & Beliefs about consequences & 3 & \\
\hline & & Beliefs about capabilities & 8 & \\
\hline & & Goals & $9-10$ & \\
\hline \multirow[t]{4}{*}{ Feedback (on behaviour) } & \multirow[t]{4}{*}{3} & Knowledge & 2 & \multirow[t]{4}{*}{ High } \\
\hline & & Beliefs about consequences & 3 & \\
\hline & & Beliefs about capabilities & 8 & \\
\hline & & Goals & $9-10$ & \\
\hline \multirow[t]{5}{*}{ Self-monitoring (behaviour) } & \multirow[t]{5}{*}{5} & Memory, attention, decision processes & 5 & \multirow[t]{5}{*}{ High } \\
\hline & & Behavioural regulation & 7 & \\
\hline & & Skills & 9 & \\
\hline & & Beliefs about consequences & 3 & \\
\hline & & Beliefs about capabilities & 8 & \\
\hline \multirow{5}{*}{$\begin{array}{l}\text { Self-monitoring (outcomes } \\
\text { behaviour) }\end{array}$} & \multirow[t]{5}{*}{3} & Memory, attention, decision processes & 5 & \multirow[t]{5}{*}{ High } \\
\hline & & Behavioural regulation & 7 & \\
\hline & & Skills & 9 & \\
\hline & & Beliefs about consequences & 3 & \\
\hline & & Beliefs about capabilities & 8 & \\
\hline \multirow[t]{5}{*}{ Social support (practical) } & \multirow[t]{5}{*}{4} & Social influences & 4 & \multirow[t]{5}{*}{ High } \\
\hline & & Beliefs about capabilities & 8 & \\
\hline & & Social professional role and identity & 6 & \\
\hline & & Intentions & $11-14$ & \\
\hline & & Goals & $9-10$ & \\
\hline \multirow{2}{*}{$\begin{array}{l}\text { Information about health } \\
\text { consequences }\end{array}$} & \multirow[t]{2}{*}{9} & Knowledge & 2 & \multirow[t]{2}{*}{ High } \\
\hline & & Beliefs about consequences & 3 & \\
\hline \multirow{2}{*}{$\begin{array}{l}\text { Information about social } \\
\text { environmental consequences }\end{array}$} & \multirow[t]{2}{*}{4} & Knowledge & 2 & \multirow[t]{2}{*}{ High } \\
\hline & & Beliefs about consequences & 3 & \\
\hline \multirow[t]{3}{*}{ Prompts/cues } & \multirow[t]{3}{*}{1} & Memory, attention, decision processes & 5 & \multirow[t]{3}{*}{ High } \\
\hline & & Environmental context and resources & 1 & \\
\hline & & Behavioural regulation & 7 & \\
\hline \multirow{2}{*}{$\begin{array}{l}\text { Restructuring the social } \\
\text { environment }\end{array}$} & \multirow[t]{2}{*}{1} & Social influences & 6 & High \\
\hline & & Environmental context and resources & 1 & \\
\hline Action planning & 1 & Goals & $9-10$ & Med \\
\hline & & Intentions & $11-14$ & \\
\hline & & Memory, attention, decision processes & 5 & \\
\hline & & Behavioural regulation & 7 & \\
\hline Information about emotional & 1 & Knowledge & 2 & Med \\
\hline consequences & & Emotions & $11-14$ & \\
\hline Social comparison & 1 & Social influences & 4 & Med \\
\hline Demonstration of the behaviour & 2 & Social influences & 4 & Med \\
\hline & & Skills & 9 & \\
\hline
\end{tabular}


Table 4 Theoretical congruence between BCTs and TDF domains (Continued)

\begin{tabular}{|c|c|c|c|c|}
\hline BCT & $\begin{array}{l}\text { Frequency } \\
(\boldsymbol{N} \text { interventions, } \\
\text { Max 11) }\end{array}$ & $\begin{array}{l}\text { Linked TDF domains according to } \\
\text { integrated linking matrix }{ }^{\mathbf{a}}\end{array}$ & $\begin{array}{l}\text { TDF domain } \\
\text { importance } \\
\text { ranking }\end{array}$ & $\begin{array}{l}\text { Theoretical congruence } \\
\text { between BCT and domain }\end{array}$ \\
\hline \multirow[t]{3}{*}{ Credible source } & \multirow[t]{3}{*}{3} & Beliefs about consequences & 3 & \multirow[t]{3}{*}{ Med } \\
\hline & & Goals & $9-10$ & \\
\hline & & Intentions & $11-14$ & \\
\hline Identification of self as a role model & 1 & Social influences & 4 & Med \\
\hline \multirow[t]{5}{*}{ Goal-setting (behaviour) } & \multirow[t]{5}{*}{4} & Behavioural regulation & 7 & \multirow[t]{5}{*}{ Low } \\
\hline & & Skills & 9 & \\
\hline & & Beliefs about capabilities & 8 & \\
\hline & & Goals & $9-10$ & \\
\hline & & Intentions & $11-14$ & \\
\hline \multirow[t]{5}{*}{ Goal-setting (outcome) } & \multirow[t]{5}{*}{1} & Behavioural regulation & 7 & \multirow[t]{5}{*}{ Low } \\
\hline & & Skills & & \\
\hline & & Beliefs about capabilities & 8 & \\
\hline & & Goals & $9-10$ & \\
\hline & & Intentions & $11-14$ & \\
\hline \multirow[t]{2}{*}{ Review behaviour goal(s) } & \multirow[t]{2}{*}{1} & Goals & $9-10$ & \multirow[t]{2}{*}{ Low } \\
\hline & & Intentions & $11-14$ & \\
\hline $\begin{array}{l}\text { Discrepancy between current } \\
\text { behaviour and goal(s) }\end{array}$ & 2 & None & $\mathrm{n} / \mathrm{a}$ & Low \\
\hline $\begin{array}{l}\text { Monitoring of outcome of } \\
\text { behaviour by others without } \\
\text { feedback }\end{array}$ & 1 & Skills & 9 & Low \\
\hline $\begin{array}{l}\text { Monitoring of the behaviour } \\
\text { by others without feedback }\end{array}$ & 3 & Skills & 9 & Low \\
\hline $\begin{array}{l}\text { Instruction on how to } \\
\text { perform the behaviour }\end{array}$ & 10 & None & N/A & Low \\
\hline \multirow[t]{4}{*}{ Reward (outcome) } & \multirow[t]{4}{*}{1} & Skills & 9 & \multirow[t]{4}{*}{ Low } \\
\hline & & Reinforcement & $11-14$ & \\
\hline & & Goals & $9-10$ & \\
\hline & & Intentions & $11-14$ & \\
\hline \multirow[t]{2}{*}{ Behavioural practice/rehearsal } & \multirow[t]{2}{*}{2} & Skills & 9 & \multirow[t]{2}{*}{ Low } \\
\hline & & Beliefs about capabilities & 8 & \\
\hline
\end{tabular}

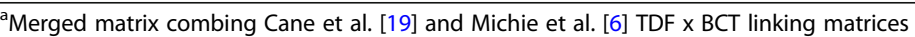

${ }^{b}$ Domain ranking based on thematic analysis of barrier/facilitator literature (see Table 2)

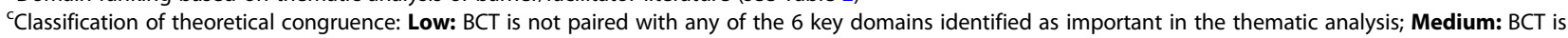
paired with at least one domain identified as important; High: BCT is paired with two or more domains identified as important

domains 'knowledge' and 'memory, attention, decisionprocesses' could potentially be targeted by the intervention functions 'education', 'training' and 'enablement.' These intervention functions were identified in 11 , four and seven interventions, respectively.

Barriers and facilitators related to the TDF domain 'environmental context and resources' could potentially be targeted by the following intervention functions: 'training', identified in four interventions; 'enablement', identified in seven interventions; and 'restriction' and 'environmental restructuring' which were not identified in any interventions representing missed opportunities to target these barriers and facilitators.

Barriers and facilitators related to the TDF domain 'social influences' could potentially be targeted through the intervention functions 'modelling' and 'enablement' (identified in two and seven interventions, respectively). They could also be targeted through the intervention functions 'restriction' and 'environmental restructuring' which were not identified in any interventions again representing missed opportunities to target these barriers and facilitators. 
Table 5 Seized and missed opportunities: intervention functions

\begin{tabular}{|c|c|c|c|c|c|c|c|c|c|}
\hline & \multicolumn{9}{|c|}{ Intervention functions (number of interventions serving each function) } \\
\hline & $\begin{array}{c}\text { Education } \\
(n=11)\end{array}$ & $\begin{array}{l}\text { Persuasion } \\
\quad(n=0)\end{array}$ & $\begin{array}{c}\text { Incentivisation } \\
(\mathrm{n}=1)\end{array}$ & Coercion $(n=0)$ & $\underset{(n=4)}{\text { Training }}$ & $\begin{array}{c}\text { Restriction } \\
(n=0)\end{array}$ & $\begin{array}{c}\text { Environmental } \\
\text { restructuring } \\
\quad(n=0)\end{array}$ & $\underset{(\mathrm{M}=2)}{\text { Modelling }}$ & $\underset{(n=7)}{\text { Enablement }}$ \\
\hline \multicolumn{10}{|l|}{ CoM-B: Physical capability* } \\
\hline \multicolumn{10}{|l|}{$\begin{array}{l}\text { COM-B: Psychological capability } \\
\text { TDF: Knowledge; Memory } \\
\text { attention, decision processes }\end{array}$} \\
\hline \multicolumn{10}{|l|}{$\begin{array}{l}\text { COM-B: Physical opportunity } \\
\text { TDF: Environmental context and } \\
\text { resources }\end{array}$} \\
\hline \multicolumn{10}{|l|}{$\begin{array}{l}\text { COM-B: Social opportunity } \\
\text { TDF: Social influences }\end{array}$} \\
\hline \multicolumn{10}{|l|}{ COM-B: Automatic motivation* } \\
\hline \multicolumn{10}{|l|}{$\begin{array}{l}\text { COM-B: Reflective motivation } \\
\text { TDF: Beliefs about consequences; } \\
\text { Social professional role and } \\
\text { identity }\end{array}$} \\
\hline $\begin{array}{l}\text { None of the six most important TDF } \\
\text { Green = Opportunity seized, i.e. a d } \\
\text { which serve the intervention functior } \\
\text { influences was identified in the syste } \\
\text { modelling and seven which served t } \\
\text { Red = Opportunity missed, i.e. an in } \\
\text { restructuring could potentially target } \\
\text { design. } \\
\text { Grey = Theoretical link between co } \\
\text { White = Not linked in matrices. }\end{array}$ & $\begin{array}{l}\text { Sains were } \\
\text { ain which is } t \\
\text { ither of restri } \\
\text { taic review as } \\
\text { function of en } \\
\text { vention functi } \\
\text { cial influence } \\
\text { B/TDF domai }\end{array}$ & $\begin{array}{l}\text { d to physical c } \\
\text { etically liked } \\
\text {,e environment } \\
\text { y infuuence on } \\
\text { ment indicatin } \\
\text { ould potentially } \\
\text { wever, we ide } \\
\text { intervention fur }\end{array}$ & $\begin{array}{l}\text { ability or automati } \\
\text { th an intervention } f \\
\text { restructuring, mod } \\
\text { AUTII-related beh } \\
\text { the opportunity to } \\
\text { arget a TDF doma } \\
\text { ified no interventio } \\
\text { tion but not releva }\end{array}$ & $\begin{array}{l}\text { ic motivation } \\
\text { function was ident } \\
\text { lelling or enableme } \\
\text { aviours. In our ana } \\
\text { design interventior } \\
\text { in but was not ider } \\
\text { ns which served th } \\
\text { nt (i.e. no importar }\end{array}$ & $\begin{array}{l}\text { For exam } \\
\text { are likely to } \\
\text { is of interve } \\
\text { vith these } r \\
\text { ed in this st } \\
\text { e interventic } \\
\text { arriers or fo }\end{array}$ & $\begin{array}{l}\text { the matrix indii } \\
\text { more effective } \\
\text { n content, we ic } \\
\text { ant intervention } \\
\text {. As described } \\
\text { unctions indicat } \\
\text { ators represent }\end{array}$ & $\begin{array}{l}\text { cates that to target } \\
\text { than other interven } \\
\text { dentififed two intere } \\
\text { f functions was seiz } \\
\text { above, using either } \\
\text { ting potential misse } \\
\text { ting them in this rev }\end{array}$ & $\begin{array}{l}\text { social influenc } \\
\text { tion functions. } \\
\text { untions which } \\
\text { ed. } \\
\text { restriction or } \\
\text { dopportunities } \\
\text { lew) }\end{array}$ & $\begin{array}{l}\text { s, interventions } \\
\text { this study, soci } \\
\text { rved the functior } \\
\text { vironmental } \\
\text { for intervention }\end{array}$ \\
\hline
\end{tabular}

The TDF domains 'beliefs about consequences' and 'social professional role and identity' could potentially be targeted through the intervention functions 'education', 'persuasion', 'incentivisation', 'coercion' and 'modelling.' 'Education' was identified in all interventions. 'Coercion' and 'persuasion' were not identified in any interventions representing a missed opportunity in all interventions. 'Incentivisation' was identified in one intervention and 'modelling' in two interventions. Whilst these are theoretically appropriate, they were identified in only a few interventions indicating that the majority of interventions missed opportunities to target barriers and facilitators related to 'beliefs about consequences' and 'social professional role and identity' using these domains.

Table 6 shows whether intervention functions identified in the 11 interventions were delivered through policy categories suggested by the $\mathrm{BCW}$ intervention function $x$ policy category matrix. All intervention functions were delivered through at least one policy category suggested by the matrix. There was one instance in Catheter Care: Royal College of Nursing Guidance for nurses where the intervention function 'modelling' was delivered through 'guidelines' (observe catheterisation performed by others on actual patients) which is not suggested by the matrix. This function was also delivered through the appropriate policy category of 'service provision' and there was a missed opportunity for it to be delivered through 'communication and marketing.'

There were missed opportunities to deliver all intervention functions identified in interventions through the policy category of 'regulation.' 'Communication/marketing', 'fiscal measures' and 'environmental and social planning' are also three potentially relevant policy categories to support identified intervention functions but were never utilised

In terms of the extent to which BCTs targeted the TDF domains in which the majority of barriers to and facilitators of CAUTI-related behaviours were identified: nine BCTs targeted two or more of the six most important TDF domains (see Table 2) and were thus classified as having high theoretical congruence, i.e. a 'match' between the intervention content and key barriers to and facilitators of CAUTI-related behaviours. These high congruence BCTs were 'feedback (on outcome of behaviour)'; 'feedback (on behaviour)'; 'self-monitoring (behaviour)'; 'selfmonitoring (outcomes behaviour)'; 'social support (practical)'; 'information about health consequences'; 'information about social environmental consequences'; 'prompts/ cues'; and 'restructuring the social environment.' Six further BCTs were classified as having medium theoretical congruence, in that they targeted only one of the six most important TDF domains: 'action planning', 'information about emotional consequences', 'social comparison', 'demonstration of the behaviour', 'credible source', and 
Table 6 Seized and missed opportunities: policy categories

\begin{tabular}{|c|c|c|c|c|c|c|c|}
\hline & \multicolumn{7}{|c|}{ Policy categories (number of interventions delivered through policy category) } \\
\hline & $\begin{array}{c}\text { Communication/ } \\
\text { marketing } \\
(\mathrm{n}=0)\end{array}$ & $\begin{array}{l}\text { Guidelines } \\
(n=9)\end{array}$ & $\begin{array}{c}\text { Fiscal measures } \\
\qquad(\mathrm{n}=0)\end{array}$ & $\begin{array}{l}\text { Regulation } \\
(n=0)\end{array}$ & $\begin{array}{l}\text { Legislation } \\
(n=1)\end{array}$ & $\begin{array}{c}\text { Environmental } \\
\text { Social planning } \\
\qquad(n=0)\end{array}$ & $\begin{array}{c}\text { Service provision } \\
(n=1)\end{array}$ \\
\hline \multicolumn{8}{|l|}{ Education } \\
\hline \multicolumn{8}{|l|}{ Persuasion } \\
\hline \multicolumn{8}{|c|}{ Incentivisation } \\
\hline \multicolumn{8}{|l|}{ Coercion } \\
\hline \multicolumn{8}{|l|}{ Training } \\
\hline \multicolumn{8}{|l|}{ Restriction } \\
\hline \multicolumn{8}{|c|}{$\begin{array}{l}\text { Environmental } \\
\text { restructuring }\end{array}$} \\
\hline \multicolumn{8}{|l|}{ Modelling } \\
\hline Enablement & & & & & & & \\
\hline $\begin{array}{l}\text { Green }=\text { Oppo } \\
\text { Red }=\text { Opportt } \\
\text { Grey }=\text { Not rel } \\
\text { Blue }=\text { Interve }\end{array}$ & $\begin{array}{l}\text { seized } \\
\text { issed }\end{array}$ & 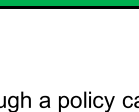 & 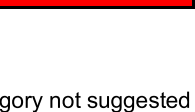 & ee matrix & & & \\
\hline
\end{tabular}

'identification of self as a role model.' However, nine BCTs in currently implemented interventions were classified as having low theoretical congruence, in that they do not target any of the six most important TDF domains influencing CAUTI-related behaviours: 'goal-setting (behaviour)'. 'goal-setting (outcome)', 'review behaviour goal(s)', 'discrepancy between current behaviour and goal(s)', 'monitoring of outcome of behaviour by others without feedback', 'monitoring of the behaviour by others without feedback', 'instruction on how to perform the behaviour', and 'reward (outcome)'.

Additional file 14 presents the frequency with which BCTs paired with important TDF domains were identified in existing interventions. BCTs paired with five of the six most important TDF domains ('knowledge', 'beliefs about consequences,' 'social influences,' 'social professional role and identity' and 'environmental context and resources) were not used frequently (i.e. less than $60 \%)$ in existing interventions. This indicates numerous missed opportunities for intervention design. Opportunity seized was highest for the TDF domains 'memory, attention and decision processes' $(100 \%$ of the theoretically coherent BCTs were used at least once in interventions) and 'knowledge' (57\% of the theoretically coherent BCTs were used at least once in interventions). The most missed opportunities were for the TDF domains social professional role and identity and environmental context and resources.

Based on the investigation of the fit between identified barriers and facilitators and BCTs, there are numerous opportunities for further intervention design and refinement. Table 7 provides initial recommendations of potential strategies to address the more frequently identified ( $n>3$ studies) barriers and facilitators within the six most important TDF domains. These recommendations include examples of different ways of delivering $\mathrm{BCT}$ s that are already included in existing interventions, or additional, new BCTs that have not been identified in current interventions but are relevant to the key TDF domains [see Additional file 6]. The hypothetical example deliveries of these BCTs are intended as illustrations for how they might be operationalised; however, in moving forward with this work, the delivery of these BCTs should be co-designed with stakeholders with 
Table 7 Recommendations for intervention design and refinement

\begin{tabular}{|c|c|c|}
\hline Theme & Proposed new BCT & Example delivery to address theme \\
\hline \multicolumn{3}{|l|}{ Environmental context and resources } \\
\hline $\begin{array}{l}\text { Limited and inconsistent documentation } \\
\text { and records }\end{array}$ & $\begin{array}{l}\text { Restructuring the physical } \\
\text { environment; prompts/ } \\
\text { cues }\end{array}$ & $\begin{array}{l}\text { Creating standardised computer-based documentation requiring staff to } \\
\text { enter reason for catheterisation, date of insertion, etc. (i.e. not circumven } \\
\text { system by leaving fields blank). }\end{array}$ \\
\hline Transitions of care & $\begin{array}{l}\text { Restructuring the social } \\
\text { environment }\end{array}$ & $\begin{array}{l}\text { Creating the rule that ward staff transferring patients to another ward } \\
\text { check with the staff receiving the patient whether catheterisation is } \\
\text { necessary (this rule could be prompted by a checklist for transfer of } \\
\text { patients to another ward/hospital or home where staff check if the } \\
\text { catheter is needed). }\end{array}$ \\
\hline $\begin{array}{l}\text { Lack of time to perform alternatives to } \\
\text { urinary catheterisation }\end{array}$ & $\begin{array}{l}\text { Adding objects to the } \\
\text { environment }\end{array}$ & $\begin{array}{l}\text { Provision of condom catheters, female urination devices and/or local } \\
\text { commodes at bedside. }\end{array}$ \\
\hline \multicolumn{3}{|l|}{ Knowledge } \\
\hline $\begin{array}{l}\text { Lack of knowledge of clinical guidelines } \\
\text { and local procedural documents }\end{array}$ & \multicolumn{2}{|c|}{$\begin{array}{l}\text { Information to consider including in guidelines/local procedural documents: } \\
\text { - Alternatives to catheterisation } \\
\text { - How to safely manage infections arising from catheterisation? } \\
\text { Whilst the information contained in the guidelines appears to address lack of knowledge in, e.g. link } \\
\text { between catheter duration and CAUTI, the issue may be more to do with dissemination. Guideline } \\
\text { implementation strategies to accompany recommendations may promote this. }\end{array}$} \\
\hline
\end{tabular}

Beliefs about consequences

Convenience and ease of monitoring

Social influences

Requests from patients and their carers

Lack of peer support and buy-in

Physicians dictate nurses' practice

Cultural norms regarding standard catheterisation practice for specific patient groups

Memory attention and decision processes

Pre-empting subsequent urinary catheterisation

\section{Anticipated regret and/or salience of consequences \\ Pros and Cons \\ Salience of consequences \\ Persuasive communication (Credible source)}

Social comparison

Demonstration of the behaviour

Information about others' approval

Restructuring the social environment

Social comparison

Social comparison

Action planning

Self-monitoring of behaviour
Getting staff to think about how they would feel if a patient was diagnosed with CAUTI after they had catheterised them for non-medical reasons (this could be delivered as part of a training programme, staff meetings, printed and electronic materials).

Encouraging staff to list the benefits and disadvantages of catheterising for convenience compared with catheterising for medical reasons (this could be delivered as a part of a training programme or suggested face to face in staff).

Providing images emphasising the severity of CAUTI.

Members of Trust leadership and senior members of staff endorsing not catheterising for convenience.

Staff convey to patients/carers that most patients/carers do not request catheters and explain the reason why this is.

Staff role modelling challenging patient/carer requests.

Informing staff engagement with CAUTI-reducing practices is encouraged by peers/senior staff.

Strategies to empower nurses to lead on catheter decision-making (delivered through peers/senior team members).

Provide examples of where the HOUDINI protocol has been effectively implemented.

Compare rates of catheterisation and corresponding rates of infection between wards/hospitals/primary care practices/nursing homes. Stratifying by professional role will increase the salience of this comparison.

Plan who will assess the patient for catheterisation and where this will happen

Document the action plan (see above) so there is agreement between staff on different wards whether the patient being transferred requires a catheter and if so, who will insert the catheter. contextual understanding of the subject area using explicit criteria.

Social professional role and identity is not included as no theme was identified in 3 or more studies
Whilst the BCTs suggested here are linked to multiple intervention functions-the matrix in Table 5 indicates the most relevant functions interventions need to serve are 'restructuring the social and physical environment' 
(none of the identified interventions serve this function), 'persuasion' and 'enablement.'

\section{Discussion}

\section{Summary of findings}

The aims of this study were to identify barriers to and facilitators of CAUTI prevention behaviours, describe the content of nationally adopted interventions and assess the extent to which intervention content is theoretically congruent with facilitators and barriers. Interventions incorporated half the potentially relevant content to target identifed barriers to and facilitators of CAUTI-related behaviours. There were missed opportunities for intervention as most focus on shaping knowledge rather than addressing motivational, social and environmental influences.

The most frequently identified barriers and facilitators related to the TDF domains: (1) 'environmental context and resources', e.g. having the time and equipment to perform alternatives to catheterisation; (2) 'knowledge'. e.g. lack of knowledge of relevant clinical guidelines; (3) 'beliefs about consequences', e.g. healthcare professionals' perceptions of severity of CAUTI and of the ease and convenience associated with catheterisation; (4) 'social Influences', e.g. family requests to catheterise the patient; (5) 'memory, attention and decision processes', e.g. making catheter-related decisions based on non-medical criteria; and (6) 'social professional role and identity', e.g. accepting responsibility for making catheter-related decisions.

We identified 11 interventions to reduce CAUTI that are implemented currently in England. These were typically in the form of clinical guidelines. All 11 interventions served the function 'education', seven served an 'enabling' function and four served a 'training' function. We identified 24 behaviour change techniques (BCTs) across the interventions. The most frequently identified BCTs were 'instruction on how to perform a behaviour' (identified in 10 interventions) with low theoretical congruence and 'information about health consequences' (identified in 9 interventions) which had high theoretical congruence. The BCT 'self-monitoring of behaviour' was identified in five interventions.

We took a generous and inclusive approach to our coding in that many interventions were prompting techniques such as monitoring, feedback and planning, rather than providing these techniques directly (e.g. guidelines including recommendations to monitor and feedback on CAUTI-related practice). We still coded for the presence of the techniques in such instances.

Combined, these findings highlight that interventions were primarily educational in nature whereas many of the barriers concerned the social and environmental context, and motivational influences of beliefs about consequences and perceptions of role. This suggests many missed opportunities for potentially effective interventions.

A number of 'missed opportunities,' for intervention design were identified in the form of theoretically congruent BCTs that are not currently included in interventions. This was particularly apparent for the TDF domains 'environmental context and resources,' and 'social professional role and identity,' for which only approximately a third of theoretically congruent BCTs were included (at least once) in existing interventions. For some TDF domains, such as 'memory, attention and decision processes,' a large proportion of congruent BCTs featured in existing interventions. These were delivered at a very low frequency suggesting a further missed opportunity for intervention design and refinement.

\section{Strengths and limitations}

There are five limitations to this study. First, bundles rather than specific behaviours tended to be the focus of studies included in the systematic review. Therefore, it was not possible to identify which barriers and facilitators related to which specific behaviours and, in turn, to provide more specific recommendations for intervention development.

Secondly, as this is a secondary content analysis of published (including grey) literature, intervention descriptions are often poorly and vaguely specified and offer limited detail for coding. In addition, we were only able to synthesise barriers and facilitators that were reported by the authors of the included studies, raising the possibility of reporting/interpretation bias. As none of the included studies investigated barriers and facilitators using the TDF, it is possible that some of the TDF domains were not frequently identified because questions were not asked to assess the role that domain plays in influencing CAUTIrelated behaviours; for example, we might hypothesise that reinforcement and emotion are likely to be important.

Thirdly, the majority of studies reporting barriers to and facilitators of CAUTI behaviours were conducted in the USA. The different geographical and health care contexts between the USA and England may limit the validity of this generalisation. Whilst the barriers and facilitators identified in the two UK studies identified in this review are comparable with non-UK studies in this review, widening the scope to the international literature allowed us to draw more robust conclusions on the barriers to and facilitators of CAUTI-related behaviours. Optimising the literature in this way has been done previously. For example, Lawrenson et al.'s 2018 HTA assessment of diabetic retinopathy screening was 
conducted primarily in the context of the UK NHS Diabetic Eye Screening Programme but included mainly studies conducted in the USA [11].

Fourthly, linking identified barriers and facilitators to CAUTI prevention behaviours with intervention content was done at an aggregate not individual level to signpost to seized and missed opportunities for intervention. Further work is required to establish the specific implications of these opportunities for individual-level interventions.

Finally, the TDF domain $\times$ BCT pairings upon which the assessments of congruence are discussed are the result of expert consensus, rating whether a TDF domain could be linked to a BCT in general (i.e. no specific context) and so do not differentiate between theoretically congruent pairings according to different types of behaviours. Therefore, some of the proposed theoretically congruent $\mathrm{BCTs}$ may not be as relevant or appropriate in the context of CAUTI.

An important factor to consider in interpreting these data is the frequency with which BCTs were identified. For example, whilst BCTs 'feedback on the outcome of behaviour' and 'information about health consequences' were both classified as having high theoretical congruence, 'feedback on the outcome of behaviour' was identified in only three interventions, whereas 'instruction on how to perform the behaviour' which had low theoretical congruence was identified in 10 interventions. We were inclusive in this linking element and so these findings may present an optimistic scenario and the actual degree of congruence could be lower than might seem.

\section{Future research directions}

The factors influencing CAUTI-related behaviours are likely to vary and differ across HCPs and settings. Further research is needed to prioritise the key behaviours influencing CAUTI within complex intervention bundles. This would allow a more focused behavioural analysis to identify the barriers to and facilitators of CAUTI-related behaviours. Using a comprehensive behavioural theory or framework, such as the TDF or $\mathrm{COM}-\mathrm{B}$, will ensure that the wide range of potential barriers to and facilitators of behaviour are consideredfrom individual-level factors to broader social and physical environmental factors. This will build on the findings here as to support establishing whether TDF domains not identified in this systematic literature are relevant to CAUTI prevention behaviours.

Most studies included in our analysis investigated the barriers to and facilitators of CAUTI-related behaviours in secondary care. However, the majority of the existing interventions analysed target primary care, community and nursing homes. This is an important discrepancy and limitation to the linking exercise we conducted to establish whether existing interventions target the key factors influencing CAUTI-related behaviours. The factors influencing CAUTI-related behaviour are likely to be context specific and thus differ across care settings. Therefore, further behavioural analysis and diagnosis research in under-investigated care settings would enable a more accurate linking of existing interventions to influences on behaviour and more targeted recommendations for intervention development.

This descriptive review did not investigate which BCTs were associated with improved outcomes in existing interventions. Subsequent work could include reviews of the published, peer-reviewed evaluations of interventions targeting CAUTI, coupled with BCT coding of these interventions and meta-regression to identify which BCTs, intervention functions and policy categories are linked to effective interventions.

Given a key finding in this work was that there was a lack of awareness of guidelines, more process evaluation research is recommended to identify why guidelines are not being implemented. Current strategies tend to be 'passive' in that they are published in the public domain, but there is no clear active dissemination to those for whom the guidelines are most relevant. Investment in the development and evaluation of implementation intervention strategies would be a first step in reducing the evidence-implementation gap.

\section{Conclusions}

The interventions identified in this work used a narrow range of strategies-primarily educational and often delivered in the form of guidelines. To better address barriers and facilitators identified in the systematic review, more proactive strategies are needed to increase the implementation of these guidelines [45]. Strategies could include effective communication to target audiences when guidelines are published across all settings; clear summary documents with key messages; implementation plans to facilitate the translation of recommendations into practice; supporting materials, e.g. training slides; auditing hospitals, GP practices and care homes against recommendations in guidelines and providing feedback on performance against these recommendations; highlighting discrepancies between observed and desired behaviours; and setting goals and action plans to reduce any observed discrepancy. Strategies such as these could also incorporate elements of social comparison such as comparing performance against other wards, teams or hospitals.

To our knowledge, this is the first time the combined behavioural tools of BCW, TDF and BCTTv1 have been applied in a policy context to understand the factors influencing a behaviour, characterise existing interventions and establish the congruence (i.e. match) between 
influences on behaviour and intervention content. These findings signpost policy-makers to where opportunities have been realised and missed in existing interventions to inform intervention refinement and the design of new interventions. In this and the WIDeR-EyeS study [13], peer-review evidence was synthesised and triangulated over 11 interventions. This method could also be applied to novel data on barriers and facilitators (e.g. interviews with relevant stakeholders) and triangulated with an individual intervention. At whichever level they are applied, these methods could increase understanding across health protection, public health and other areas of implementation research.

\section{Supplementary information}

Supplementary information accompanies this paper at https://doi.org/10. 1186/s13012-020-01001-2.

Additional file 1. Labels, definitions and examples of COM-B and Theoretical Domains Framework

Additional file 2. Behaviour Change Wheel labels, definitions and examples

Additional file 3. BCW matrices

Additional file 4. Adherence to reporting guidelines

Additional file 5. Electronic search strategies

Additional file 6. Merged Theoretical Domain Framework x Behaviour Change Techniques matrices

Additional file 7. Flow of information through the systematic review

Additional file 8. MMAT study quality rating

Additional file 9. Summary of barriers to and facilitators of CAUTIrelated behaviours

Additional file 10. All reported barriers and facilitators within each TDF domain** identified across all care settings (primary, community, secondary and tertiary care, and care homes), nested according to COM-

Additional file 11. Description of included nationally adopted interventions in England to reduce CAUTI

Additional file 12. BCTs, intervention functions and policy categories identified in each intervention

Additional file 13. Examples of BCT identification

Additional file 14. Opportunities for intervention design: the frequency with which theoretically congruent BCTs with important theoretical domains were used in existing interventions

\section{Acknowledgements}

The authors thank PHE interns Paulina Bondaronek and Marta Gonzalezlraizoz for their assistance in data extraction.

\section{Authors' contributions}

$\mathrm{TC}$, ASallis and AB conceived the study. LA, FL and SM designed the study. LA and ASchneider collected the data. LA and FL analysed the data. LA, FL and SM interpreted the results. LA, FL and AS drafted the manuscript. All authors contributed to revisions of the manuscript and read and approved the final manuscript.

\section{Funding}

This project was funded by Public Health England.

\section{Availability of data and materials}

The datasets used and/or analysed during the current study are available from the corresponding author on reasonable request.
Ethics approval and consent to participate

Not applicable.

\section{Consent for publication}

Not applicable.

\section{Competing interests}

SM serves on the editorial board of Implementation Science. ASallis, TC, AB, $\mathrm{KS}$ and $\mathrm{SH}$ are employed by project funders, Public Health England. All other authors declare that they have no competing interests.

\section{Author details}

${ }^{1}$ Centre for Behaviour Change, University College London, Alexandra House, 7-19 Queens Square, London WC1N 3AZ, UK. ²Public Health England, Wellington House, 133-155 Waterloo Road, London SE1 8UG, UK.

Received: 3 October 2019 Accepted: 18 May 2020

Published online: 06 July 2020

\section{References}

1. Domin MA. Highly virulent pathogens--a post antibiotic era? $\mathrm{Br} \mathrm{J}$ Theatr Nurs. 1998;8(2):14-8

2. Fishman N. Antimicrobial stewardship. Am J Med. 2006;119(6 Suppl 1):S5361 discussion S62-70.

3. Loveday HP, Wilson JA, Pratt RJ, Golsorkhi M, Tingle A, Bak A, et al. epic3: national evidence-based guidelines for preventing healthcare-associated infections in NHS hospitals in England. J Hosp Infect. 2014;86(Suppl 1):S170 .

4. Adams D, Bucior H, Day G, Rimmer J-A, et al. J Infect Prev. 2012;13(2):44-6.

5. Codd J. Implementation of a patient-held urinary catheter passport to improve catheter management, by prompting for early removal and enhancing patient compliance. J Infect Prev. 2014;15(3):88-92.

6. Michie S, Johnston M, Francis J, Hardeman W, Eccles MP, et al. Appl Psychol. 2008;57(4):660-80

7. Michie S, van Stralen MM, West R. The behaviour change wheel: a new method for characterising and designing behaviour change interventions. Implement Sci. 2011;6:42.

8. Michie S, Richardson M, Johnston M, Abraham C, Francis J, Hardeman W, et al. Ann Behav Med. 2013;46(1):81-95.

9. Michie S, Atkins L, West R. The behaviour change wheel - a guide to designing interventions. Great Britain: Silverback Publishing; 2014

10. Steinmo SH, Michie S, Fuller C, Stanley S, Stapleton C, Stone SP. Bridging the gap between pragmatic intervention design and theory: using behavioural science tools to modify an existing quality improvement programme to implement "sepsis six", Implementation science. 2016;11(1): 14.

11. Lawrenson JG, Graham-Rowe E, Lorencatto F, Burr J, Bunce C, Francis JJ, et al. Interventions to increase attendance for diabetic retinopathy screening. Cochrane Database Syst Rev. 2018;1:Cd012054

12. Graham-Rowe E, Lorencatto F, Lawrenson JG, Burr JM, Grimshaw JM, Ivers $\mathrm{NM}$, et al. Barriers to and enablers of diabetic retinopathy screening attendance: a systematic review of published and grey literature. Diabet Med. 2018:35(10):1308-19.

13. Lawrenson JG, Graham-Rowe E, Lorencatto F, Rice S, Bunce C, Francis JJ, et al. What works to increase attendance for diabetic retinopathy screening? An evidence synthesis and economic analysis. Health Technol Assess. 2018; 22(29):1-160.

14. Pluye, P. Robert, E. Cargo, M. Bartlett, G. O'Cathain, A. Griffiths, F. Boardman, F. Gagnon, MP. Rousseau, MC. Proposal: a mixed methods appraisal tool for systematic mixed studies reviews. 2011. Available from: http:// mixedmethodsappraisaltoolpublic.pbworks.com/FrontPage. Cited 2018.

15. Srivastava, A. and S. Thompson, Framework analysis: a qualitative methodology for applied policy research. Journal of Administration and Governance. 2009:4:(2)

16. Braun V, Clarke V. Using thematic analysis in psychology. Qual Res Psychol. 2006:3(2):77-101.

17. Atkins L, Francis J, Islam R, O'Connor D, Patey A, Ivers N, et al. A guide to using the theoretical domains framework of behaviour change to investigate implementation problems. Implement Sci. 2017;12(1):77. 
18. Michie S, Johnston M, Francis J, Hardeman W, Eccles M. From theory to intervention: mapping theoretically derived behavioural determinants to behaviour change techniques. Appl Psychol. 2008;57(4):660-80.

19. Cane J, Richardson M, Johnston M, Ladha R, Michie S. From lists of behaviour change techniques (BCTs) to structured hierarchies: comparison of two methods of developing a hierarchy of BCTs. Br J Health Psychol. 2015;20(1):130-50

20. Getliffe $K$, Newton T. Catheter-associated urinary tract infection in primary and community health care. Age \& Ageing. 2006;35(5):477-81.

21. Krein SL, Harrod M, Collier S, Davis KK, Rolle AJ, Fowler KE, et al. A national collaborative approach to reduce catheter-associated urinary tract infections in nursing homes: a qualitative assessment. American Journal of Infection Control. 2017:45(12):1342-8.

22. Krein SL, Kowalski CP, Harrod M, Forman J, Saint S. Barriers to reducing urinary catheter use: a qualitative assessment of a statewide initiative. JAMA Intern Med. 2013;(10):173, 881-6.

23. Harrod M, Kowalski CP, Saint S, Forman J, Krein SL. Variations in risk perceptions: a qualitative study of why unnecessary urinary catheter use continues to be problematic. BMC Health Serv Res. 2013;13:151.

24. Alexaitis I, Broome B. Implementation of a nurse-driven protocol to prevent catheter-associated urinary tract infections. J Nurs Care Qual. 2014;29(3):245-52.

25. Andreessen L, Wilde MH, Herendeen P. Preventing catheter-associated urinary tract infections in acute care: the bundle approach. J Nurs Care Qual. 2012;27(3):209-17.

26. Apisarnthanarak A, Ratz D, Greene MT, Khawcharoenporn T, Weber DJ, Saint S. National survey of practices to prevent health care-associated infections in Thailand: the role of prevention bundles. Am J Infect Control. 2017;45(7): 805-10.

27. Bursle EC, Dyer J, Looke DF, McDougall DA, Paterson DL, Playford EG. Risk factors for urinary catheter associated bloodstream infection. J Infect. 2015; 70(6):585-91.

28. Carter EJ, Pallin DJ, Mandel L, Sinnette C, Schuur JD. Emergency department catheter-associated urinary tract infection prevention: multisite qualitative study of perceived risks and implemented strategies. Infect Control Hospl Epidemiol. 2016;37(2):156-62

29. Carter EJ, Pallin DJ, Mandel L, Sinnette C, Schuur JD. A qualitative study of factors facilitating clinical nurse engagement in emergency department catheter-associated urinary tract infection prevention. J Nurs Adm. 2016; 46(10):495-500

30. Hu FW, Yang DC, Huang CC, Chen CH, Chang CM. Inappropriate use of urinary catheters among hospitalized elderly patients: clinician awareness is key. Geriatr Gerontol Int. 2015;15(12):1235-41.

31. Conner BT, Kelechi TJ, Nemeth LS, Mueller M, Edlund BJ, Krein SL. Exploring factors associated with nurses' adoption of an evidence-based practice to reduce duration of catheterization. J Nurs Care Qual. 2013;28(4):319-26.

32. Conway LJ, Pogorzelska M, Larson E, Stone PW. Adoption of policies to prevent catheter-associated urinary tract infections in United States intensive care units. Am J Infect Control. 2012:40(8):705-10.

33. Crouzet J, Bertrand X, Venier AG, Badoz M, Husson C, Talon D. Control of the duration of urinary catheterization: impact on catheter-associated urinary tract infection. J Hosp Infect. 2007;67(3):253-7.

34. Dugyon-Escalante J, Yoon J, Lavelle J, Naungayan A. The impact of multidisciplinary team approach to combat catheter associated urinary tract infection in a large government hospital. Am J Infect Control. 2015;43(6 Supplement 1):S45-6.

35. Fakih MG, Dueweke C, Meisner S, Berriel-Cass D, Savoy-Moore R, Brach N, et al. Effect of nurse-led multidisciplinary rounds on reducing the unnecessary use of urinary catheterization in hospitalized patients. Infect Control Hosp Epidemiol. 2008;29(9):815-9.

36. Fakih MG, George C, Edson BS, Goeschel CA, Saint S. Implementing a national program to reduce catheter-associated urinary tract infection: a quality improvement collaboration of state hospital associations, academic medical centers, professional societies, and governmental agencies. Infect Control Hosp Epidemiol. 2013;34(10):1048-54.

37. Gupta SS, Irukulla PK, Shenoy MA, Nyemba V, Yacoub D, Kupfer Y. Successful strategy to decrease indwelling catheter utilization rates in an academic medical intensive care unit, Am J Infect Control. 2017;45(12):1349-55.

38. Mann P, Vandygriff C, Kingsberry L, Horne R, Strelczyk K. Catheter-associated urinary tract infection (CAUTI): a significant case for concern. Am J Infect Control. 2013;1:-S124.
39. Murphy C, Prieto J, Fader M. "It's easier to stick a tube in": a qualitative study to understand clinicians' individual decisions to place urinary catheters in acute medical care. BMJ Quality \& Safety. 2015;24(7):444-50.

40. Patrizzi K, Fasnacht A, Manno M. A collaborative, nurse-driven initiative to reduce hospital-acquired urinary tract infections. J Emerg Nurs. 2009;35(6): $536-9$.

41. Smith LC, Peyton J, Krout K, Cox CA, Huber KL. Decreasing the rate of catheter-associated urinary tract infections through a nurse-driven intervention. J Burn Care Res. 2015;36:S147.

42. Fakih MG, Pena ME, Shemes S, Rey J, Berriel-Cass D, Szpunar SM, et al. Effect of establishing guidelines on appropriate urinary catheter placement. Acad Emerg Med. 2010;17(3):337-40.

43. Trautner BW, Petersen NJ, Hysong SJ, Horwitz D, Kelly PA, Naik AD, et al. Am J Infect Control. 2014;42(6):653-8.

44. Kolonoski P, Stanley K, Anderson K. An interdisciplinary approach toward reducing the incidence of catheter-associated urinary tract infections in a post-acute facility. Am J Infect Control. 2012;40(5):e54-5.

45. Grol R, Grimshaw J. From best evidence to best practice: effective implementation of change in patients' care. Lancet. 2003;362(9391):1225-30.

\section{Publisher's Note}

Springer Nature remains neutral with regard to jurisdictional claims in published maps and institutional affiliations.
Ready to submit your research? Choose BMC and benefit from:

- fast, convenient online submission

- thorough peer review by experienced researchers in your field

- rapid publication on acceptance

- support for research data, including large and complex data types

- gold Open Access which fosters wider collaboration and increased citations

- maximum visibility for your research: over $100 \mathrm{M}$ website views per year

At BMC, research is always in progress.

Learn more biomedcentral.com/submissions 